\title{
Analysis of referrals to the stomatology service in a Southern Brazilian hospital: a retrospective study
}

\author{
Gisele Corrêa de Oliveira \\ ZIGMUNDO(a) $^{(a)}$ \\ Tuany Rafaeli SCHMIDT(a) \\ Felipe Martins SILVEIRA ${ }^{(b)}$ \\ Matheus NEVES(c) iD \\ Marco Antônio Trevizani \\ MARTINS(d) iD \\ Vinicius Coelho CARRARD(a) \\ Manoela Domingues MARTINS(a) \\ (a) Universidade Federal do Rio Grande do Sul \\ - UFRGS, School of Dentistry, Department \\ of Oral Pathology, Porto Alegre, RS, Brazil. \\ (b) Universidade Estadual de Campinas, \\ Piracicaba Dental School, Department of \\ Oral Diagnosis, Piracicaba, SP, Brazil. \\ (c) Universidade Federal do Rio Grande do Sul \\ - UFRGS, School of Dentistry, Department of \\ Preventive Dentistry, Porto Alegre, RS, Brazil. \\ (d) Hospital de Clínicas de Porto Alegre - \\ HCPA, Department of Stomatology, Porto \\ Alegre, RS, Brazil.
}

Declaration of Interests: The authors certify that they have no commercial or associative interest that represents a conflict of interest in connection with the manuscript.

\section{Corresponding Author:}

Manoela Domingues Martins

E-mail: manomartins@gmail.com

https://doi.org/10.1590/1807-3107bor-2021.vol35.0072

Submitted: Augst 6, 2020

Accepted for publication: December 22, 2020

Last revision: February 17, 2021

\begin{abstract}
This paper intends to describe the demand for referrals to the stomatology service requested by the medical teams for inpatients in a reference hospital in the south of Brazil. This research is a retrospective cross-sectional descriptive study focusing on data collection and assessment of information about referrals to the stomatology unit carried out from January 2008 to December 2018. All information was obtained from the hospital management software database, then transferred and analyzed individually for descriptive statistics. A total of 4433 cases were referred to the stomatology team, with an average of 403 cases by year. Hematology/hemato-oncology (37.3\%) was the specialty asking for the majority of the referrals, followed by Oncology (20.4\%) and Pneumology (8.2\%). The mean patients' profile was males (55.5\%), receiving a diagnosis of oral mucositis $(43.5 \%)$, and with the first and second decades of life being the most prevalent ones $(34.9 \%)$, with a mean age of $34.8 \pm 22.3$ years. The most common treatment performed by the stomatology team was the photobiomodulation therapy $(44.8 \%)$. This retrospective study demonstrated the important profile of the stomatological care in hospitalized patients from a specific hospital, especially referred by the hematology/hemato-oncology team. These results evidenced the importance of the stomatology specialty in the hospital environment.
\end{abstract}

Keywords: Oral Medicine; Epidemiology; Stomatology; Stomatitis; Medical Oncology.

\section{Introduction}

Dental care provided to hospitalized patients involves the concept of complete health care, considering the oral condition as an important factor in establishing and promoting the individual's general health. ${ }^{1}$ Dental surgeons are responsible for sharing responsibilities with other members of the multidisciplinary team, contributing to the completeness of care. ${ }^{2}$

The interactions and synergisms between systemic diseases, medications and hospital infections with the oral conditions present in the patient throughout the hospitalization are an important issue to be considered by health professionals. ${ }^{3,45}$ For instance, hospital infections that account for significant mortality can be minimized or even prevented by providing effective oral hygiene protocols, particularly in patients submitted to mechanical ventilation. ${ }^{6}$ 
In this context, the dentist can also provide oral health care for the cancer patient. ${ }^{7,8}$ Mainly due to the depression of the immune system during the antineoplastic treatment, oral diseases such as caries and periodontitis can eventually impact the progress of the treatment, as well as the prognosis and quality of life of these patients. ${ }^{910}$ Also, chemotherapy and radiotherapy treatment can negatively impact the oral cavity potentially generating side effects such as oral mucositis, dysgeusia, xerostomia, immunosuppressive ulcerations, gingival hemorrhages from thrombocytopenia, disorders in the formation of dental germs, and opportunistic infections such as candidiasis and recurrent herpes simplex..$^{8,11,12} \mathrm{In}$ the reference service analyzed in the present study, the hospital care specialties can refer inpatients to the stomatology team for evaluations, diagnosis, and treatment of an array of diseases that may affect the oral cavity. Procedures conducted in the referrals were performed with the inpatient in the hospital bed within the requesting service unit. However, when patients' condition does not impair their mobility, it's preferred to move the inpatient to the stomatology care unit for certain procedures such as biopsies. It is possible to establish a process of multi-professional co-responsibility, in which the teams work in a single objective, deconstructing actions and fragmented knowledge, providing health and well-being. ${ }^{2,13,14}$ Therefore, this study aims to describe the referrals to the stomatology team of a public hospital, discuss the importance of the presence of this specialty in a hospital environment, and the profile of the population benefited by the services offered.

\section{Methodology}

\section{Study design}

This is a retrospective cross-sectional descriptive study, based on data collected from electronic records from January 2008 to December 2018. The population comprised the totality of referrals to the stomatology team, archived in the database of the software used in the hospital institution. This study was approved by the Ethics Committee on Human Research of Clinics Hospital of Porto Alegre - Brazil (approval No. 73913017.3.0000.5327).

\section{Data collection}

The inclusion criteria were based on all the referrals to the stomatology team of patients in the past eleven years. The software Microsoft Excel $2010^{\circledR}$ was used to register and organize the collected data received by an independent researcher. Once the data was organized, a second researcher assessed the data collection outcome. Unnecessary or incomplete information, duplicate data, multiple responses to the same request, and referrals mistakenly performed by the medical team were finally excluded.

From the 5.824 data initially compiled, 363 cases were excluded since it corresponded to duplicate requests in the system, 969 because it was multiple responses to the same request by the stomatology team, 32 because it was not referrals under the stomatology response, and 27 with incomplete information. Finally, 4.433 referrals were obtained.

\section{Study variables}

The information about the patient's profile was manually assessed.

Patient information: name; age (in years); gender (female and male); education (absent, incomplete elementary school, complete elementary school, incomplete high school, incomplete higher education, complete higher education, and ignored) and International Classification of Diseases (ICD) of internment (Sorted by ascending alphanumeric order, description of the most prevalent is included in the sample).

Information on requests: requesting specialty (cardiology, gastroenterology, emergency, psychiatry, hematology/hemato-oncology, oncology, pneumology, internal medicine, nephrology, pediatrics, and others); status of care (attended and not attended); and reason for the referral (oral mucosal lesions, dental need, pre-transplant evaluation or heart surgery, and general evaluation of the oral cavity).

Information on the answers: hypothesis of diagnosis (mucositis, need for complementary exams, reactive lesions, oral infectious diseases, dental diseases, periodontal diseases, immunological diseases, malignant neoplasms of the mouth and others); conducts (photobiomodulation, request for complementary exams, dental procedures, biopsies, 
surgical procedures- osteotomy, extractions, abscess drainage, and others, and others); and follow-up time (in days).

\section{Statistical analysis}

Statistical Package for the Social Sciences - SPSS ${ }^{\circledR}$ software was used to describe the quantitative variables age and follow-up time, according to the measures of central tendency and variability, by mean and standard deviation. The qualitative variables were categorized and described in their absolute and relative frequencies.

\section{Results}

A total of 4.433 referrals were assessed in this study, of which 4.136 (93.3\%) were attended and 297 (6.7\%) were not attended by the stomatology team. The average of referrals per year was 403, and the year 2013 (625 cases; 14.1\%) was the period that registered the highest number of cases, followed by 2014 (546 cases; 12.3\%) and 2012 (531 cases;12.0\%). The full distribution of referrals by year is presented in Figure.

\section{Patient's profile}

The information about the patient's profile attended in referrals are described in Table 1 . The majority of the population was single $(62.8 \%)$ and male (55.5\%). The age at the time of hospital admission varied from 0 to 96 years, with a mean age of $34.8 \pm 22.3$ years. Additionally, the second decade of life was the most prevalent (779 cases; $17.6 \%$ ) followed by the first decade of life (768 cases; $17.3 \%$ ). The Public Health System was the hospitalization agreement applied in 3.927 (88.6\%) of the referrals and admissions, while only 506 (11.4\%) were applied by the private system.

\section{Request information}

The information about the medical team that requested the stomatology evaluation and the reason for the request is shown in Table 2. The most common medical teams referring inpatients to the stomatology unit were hematology/hemato-oncology and oncology with a total of 2.558 requests $(57.7 \%)$.

\section{Response information}

From the 4.433 referrals, 4.136 (93.3\%) were responded. The hypothesis of diagnosis, clinical conduct of the stomatology team, and the time of follow-up are described in Table 3. Despite the impossibility of accounting for them, the main reasons why referrals were not answered (6.7\%) are due to death or discharge before the team's evaluation, or absence of progress.

Oral mucositis was the most common diagnosis established, accounting for a total of 1.927 cases

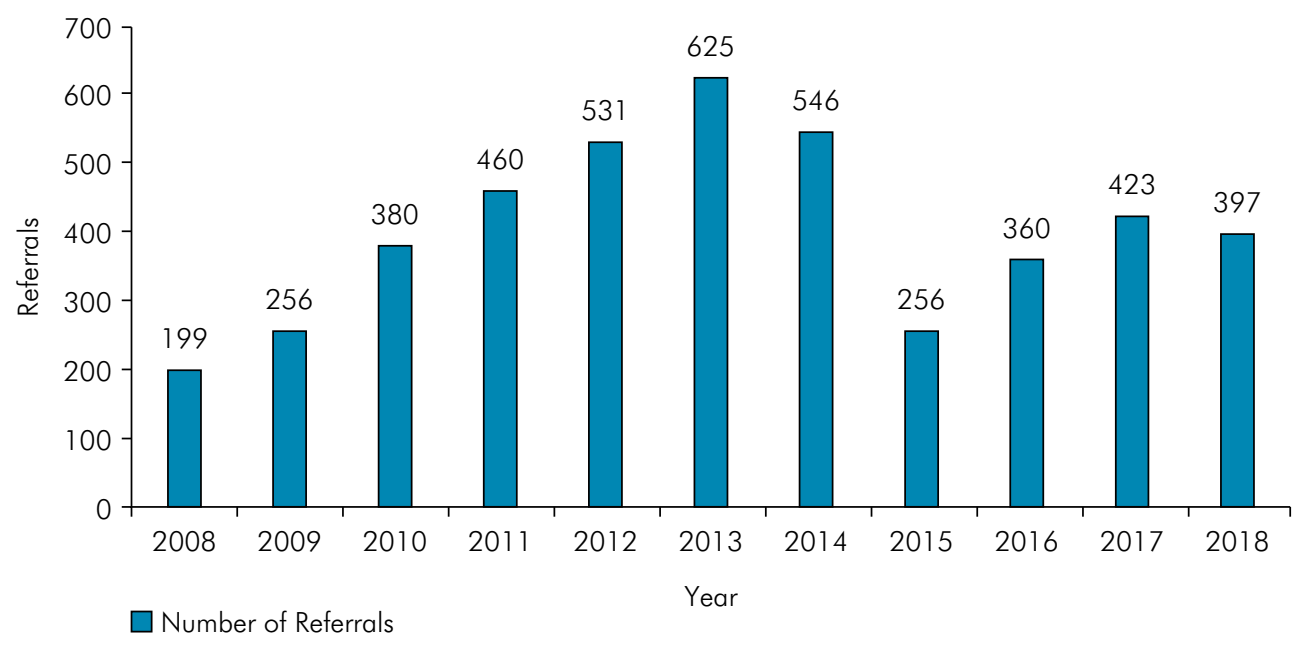

Figure. Distribution of referrals by year. 
Table 1. Simple (n) and relative (\%) frequencies of data related to the patient.

\begin{tabular}{|c|c|c|}
\hline Variables & Frequency (n) & Percentage $(\%)$ \\
\hline \multicolumn{3}{|l|}{ Gender } \\
\hline Male & 2459 & 55.5 \\
\hline Female & 1974 & 44.5 \\
\hline Total & 4433 & 100 \\
\hline \multicolumn{3}{|l|}{ Age } \\
\hline First decade of life & 768 & 17.3 \\
\hline Second decade of life & 779 & 17.6 \\
\hline Third decade of life & 498 & 11.2 \\
\hline Fourth decade of life & 497 & 11.2 \\
\hline Fifth decade of life & 521 & 11.8 \\
\hline Sixth decade of life & 730 & 16.5 \\
\hline Seventh decade of life & 431 & 9.7 \\
\hline Eighth to Tenth decade of life & 209 & 4.7 \\
\hline Total & 4433 & 100 \\
\hline \multicolumn{3}{|l|}{ Education } \\
\hline Absent & 678 & 15.3 \\
\hline Incomplete elementary school & 1669 & 37.6 \\
\hline Complete elementary school & 535 & 12.1 \\
\hline Incomplete high school & 300 & 6.8 \\
\hline Complete high school & 697 & 15.7 \\
\hline Incomplete higher education & 146 & 3.3 \\
\hline Complete higher education & 275 & 6.2 \\
\hline lgnored & 133 & 3.0 \\
\hline Total & 4433 & 100 \\
\hline \multicolumn{3}{|l|}{ International Classification of Disease (ICD) of Hospitalization } \\
\hline Malignant neoplasms & 2153 & 48.6 \\
\hline Some infectious and parasitic diseases & 366 & 8.2 \\
\hline Mental and behavioral disorders & 319 & 7.2 \\
\hline Circulatory system diseases & 307 & 6.9 \\
\hline Respiratory tract diseases & 189 & 4.3 \\
\hline Hematopoietic blood and organ diseases and some immune disorders & 182 & 4.1 \\
\hline Factors influencing health status and contact with health services & 155 & 3.5 \\
\hline Digestive tract diseases & 146 & 3.3 \\
\hline Abnormal symptoms, signs and findings of lab-based clinical examinations, unclassified elsewhere & 128 & 2.9 \\
\hline Endocrine, nutritional and metabolic diseases & 103 & 2.3 \\
\hline Other & 385 & 8.7 \\
\hline Total & 4433 & 100 \\
\hline
\end{tabular}

(43.5\%). The most usual procedure performed by the stomatology team was the photobiomodulation therapy, which was the elected treatment for $100 \%$ of cases of oral mucositis. Other conducts are demonstrated in Table 3. The average follow-up time of demands was 2.5 days $(\mathrm{SD} \pm 5.0)$, ranging from 0 to 55 days.

\section{Discussion}

During the process of assisting an inpatient it is possible to visualize the multidisciplinary action between professionals from different areas and the establishment of comprehensive health.,13 This study described the demand for referrals to the 
Table 2. Simple (n) and relative (\%) frequencies of data related to referrals.

\begin{tabular}{|c|c|c|}
\hline Variables & Frequency (n) & Percentage (\%) \\
\hline \multicolumn{3}{|l|}{ Requesting speciality } \\
\hline Hematology/hemato-oncology & 1653 & 37.3 \\
\hline Oncology & 905 & 20.4 \\
\hline Pneumology & 363 & 8.2 \\
\hline Psychiatry & 320 & 7.2 \\
\hline Cardiology & 237 & 5.3 \\
\hline Gastroenterology & 160 & 3.6 \\
\hline Pediatrics & 145 & 3.3 \\
\hline Emergency & 98 & 2.2 \\
\hline Intensive Care Medicine & 92 & 2.1 \\
\hline Nephrology & 81 & 1.8 \\
\hline Other & 379 & 8.6 \\
\hline Total & 4433 & 100 \\
\hline \multicolumn{3}{|l|}{ Reason for the request } \\
\hline Oral mucosal lesion & 2815 & 63.5 \\
\hline Dental need & 1408 & 31.8 \\
\hline General evaluation & 113 & 2.5 \\
\hline Pre-transplant evaluation/heart surgery & 97 & 2.2 \\
\hline Total & 4433 & 100 \\
\hline
\end{tabular}

Table 3. Simple (n) and relative (\%) frequencies of data related to demand responded.

\begin{tabular}{lcc}
\hline Variables & Frequency (n) & Percentage (\%) \\
\hline Hypothesis of diagnosis & 1927 & 46.60 \\
Oral mucositis & 773 & 18.7 \\
Dental diseases & 311 & 7.5 \\
Periodontal diseases & 282 & 6.8 \\
Need for additional exams & 220 & 5.3 \\
Infectious oral diseases & 200 & 4.8 \\
Reactional injuries & 173 & 4.2 \\
Immunological diseases & 23 & 0.6 \\
Malignant neoplasms of the mouth & 227 & 5.5 \\
Other & 4136 \\
Total & 100 \\
Procedures/Conduct & 1985 & 48.0 \\
Photobiomodulation & 831 & 20.1 \\
Dental procedures & 628 & 15.2 \\
Request for additional exams & 455 & 11.0 \\
Surgical procedures (osteotomy, extractions, abscess drainage, and others) & 117 \\
Biopsies & 2.8 \\
Other & 120 & 100 \\
Total & 4136 & 100 \\
\hline
\end{tabular}

stomatology team and highlighted the hospitalized patient's profile from a specific hospital. Our results showed that hematology/hemato-oncology medical team was the most demanding specialty, mainly motivated by the presence of oral mucosal lesions related to cancer treatment. Therefore, the main 
demand was the diagnosis and management of oral mucositis associated with oncologic treatment with a profile of children and adolescents, male, and with a low level of education.

In the 11-year period evaluated in the present study, many referrals were sent (4.433) by several medical teams and whose response rate from the stomatology team was equivalent to $93.3 \%$. After evaluation, 4.223 diagnoses were performed (2.815 oral mucosal lesions and 1.408 dental diseases - caries, periodontal disease, pulp necrosis, among others). The results showed a progressive growth in referrals made until the year of 2013 and a decrease afterward. This change in the trend is justified by the restructuring actions that occurred in the dental sector aiming to improve the care for inpatients, such as the implementation of specialized oral hygiene programs and the expansion of the specialty with the arrival of dental residency programs in Stomatology, Oral and Maxillofacial Surgery, Periodontics, and Family Health.

The present study demonstrated that the profile of the patients is mostly comprised of male individuals (55.5\%), children and young people (34.9\%), and with a low level of education (37.6\%). There was a prevalence of patients with malignant neoplasms (48.6\%), under-treatment of the hematology/hemato-oncology team $(37.3 \%)$. These data are following the demographic profile of the involvement of acute hematological malignancies, which have a certain predilection for individuals of a younger age. ${ }^{15,16}$ In addition, the treatment of different types of leukemia and lymphomas are based on systemic therapy using cytotoxic agents that leads to important oral toxicity that need stomatology team support. ${ }^{15}$

Among the diagnosed lesions, oral mucositis was the most prevalent one (43.5\%). There are several unwanted effects related to the anticancer therapy in the oral cavity, being the oral mucositis the most common condition. ${ }^{17,18}$ The term mucositis refers to an inflammatory process of the oral and/or gastrointestinal mucosa in response to systemic or local toxicity caused by antineoplastic treatment. ${ }^{19} \mathrm{In}$ patients with lymphomas and leukemias, the incidence of lesions is variable, reaching $81.82 \%$. In these patients, the reason for the high prevalence of mucositis is due to the more frequent need for the use of extremely myeloablative therapies..$^{20}$ The management of oral mucositis is of paramount importance because in severe grades it may significantly interferes with quality of life, prognosis, extended hospitalization needs, risk of secondary infections, treatment interruption, mobility, and mortality of cancer patients. ${ }^{19,20}$ Patients submitted to hematopoietic stem cell transplantation that developed oral mucositis in ulcerative forms (WHO grades 2, 3 and 4) had an increase of up to $\$ 42,749$ per transplant/patient. ${ }^{21}$ Mucositis is, therefore, a costly adverse event with oftentimes significant expenditures; consequently, the stomatology group is frequently requested for clinical evaluation and developed preventive/treatment strategies for oral mucositis and other oral complications. ${ }^{22}$

There are several resources used to prevent and/or treat oral mucositis lesions such as basic oral hygiene, use of growth factors and cytokines, anti-inflammatories, anesthetics, analgesics, antimicrobials, photobiomodulation, cryotherapy, among various natural agents. ${ }^{23}$ Photobiomodulation therapy has been demonstrating evidence of stimulation of cell proliferation, modulation of inflammatory process, resulting in the improvement of oral wound. ${ }^{24,25,26}$ These results of photobiomodulation therapy in the attenuation of oral mucositis lesions indicated it as a recommended tool for the prevention of oral mucositis in the latest publications of the Multinational Association of Supportive Care in Cancer (MASCC). ${ }^{27}$ In the present study, photobiomodulation was the therapy of choice in $100 \%$ of patients with oral mucositis. It was also used in other diagnosed inflammatory conditions and therefore represented $44.8 \%$ of the procedures performed.

Investigations regarding oral health conditions in hospitalized patients have already been described. $28,29,30$ Bertaud-Gounot et al., ${ }^{31}$ evaluated the oral health status of institutionalized psychiatric patients in a hospital with free-demand dental service. Their results showed that these patients presented four times more decayed teeth than the general population. A high prevalence of dental diseases in patients with varied systemic conditions was also reported by Carrilho Neto et al., ${ }^{32}$ where caries lesions were present in $60 \%$ of the evaluated patients. However, to the best of our knowledge, no other studies 
demonstrating specific action of the stomatology area in a hospital environment, especially in a clinical center with multiple medical specialties, were performed. Therefore, the presented characteristics in this manuscript are an unprecedented character. Additionally, studies on surveying hospital dental demands usually demonstrate the prevalence of oral diseases from the perspective of the general dentist or other specialists. ${ }^{4,8,30}$

Our results showed that stomatology appeared as an important specialty in the context of care for patients admitted to the hospital. Stomatology is a dental specialty directly related to the prevention, diagnosis, and management of oral lesions including the interaction between oral and systemic health. ${ }^{33}$ These characteristics, combined with a long training in the practice of complex diagnoses, management of orofacial diseases, and a unique capacity for interdisciplinary communication highlights the role of this professional in the daily hospital appointments. ${ }^{33,34,35}$ It is important to mention that our results may reflect the continuous interest of our stomatology team for searching of support and recognition in the hospital environment. In this sense, our group actively seek to participate in the multidisciplinary discussions related to oncology that occurs in the hospital. Consequently, it may be inferred that our active participation is continuously motivating the different teams from the hospital in requesting the stomatology support. We therefore believe that this increasing recognition of the importance of our stomatology team in the hospital may be related to the high demand of requests by the medical teams observed in this study. Farah et al., ${ }^{36}$ suggested that the diffusion of the role of a stomatology specialist is what motivates the referrals from other medical teams to this specialty. Therefore, it seems that our promising results can also be achieved in other institutions by mainly encouraging integrative actions between different teams.
This research has limitations regarding the fact that the database was composed of information provided by the patient's referral team from this specific hospital. In this context, it is important to highlight that the results of this study do not allow external extrapolation since it is specific for the scenario of this analyzed reference public hospital in a developing country. Research on hospital referrals for certain services, such as those included in this study, may elucidate the patient's profile and their health demands as well as presenting the conditions of health services. Considering the data obtained, it is possible to deliberate on the importance of creating and approving public policies that recognize the services provided by the different dental specialties in the hospital environment, endorsing the maintenance and promotion of the population's health.

\section{Conclusion}

This research showed an important demand for referrals to the stomatological care unit for hospitalized patients, especially by the hematology/hemato-oncology team. The main condition observed was oral mucositis, and it was often treated with photobiomodulation therapy. The presence of a stomatology professional is extremely important in hospitals, mainly those with a cancer care unit and treating patients with lymphoid and hematological neoplasms. Actions concerned with the diffusion of the knowledge about the stomatology should be encouraged.

\section{Acknowledgements}

This study was funded by the Postgraduate Research Group of the Hospital de Clínicas de Porto Alegre (GPPG/ FIPE: 16-0437). We would like to thank the Brazilian National Council for Scientific and Technological Development for financial support (CNPq). M.D.M is research fellows of CNPq.

\section{References}

1. Bellissimo-Rodrigues WT, Menegueti MG, Gaspar GG, Souza HC, Auxiliadora-Martins M, Basile-Filho A, et al. Is it necessary to have a dentist within an intensive care unit team? Report of a randomised clinical trial. Int Dent J. 2018 Dec;68(6):420-7. https://doi.org/10.1111/idj.12397 
2. Taberna M, Gil Moncayo F, Jané-Salas E, Antonio M, Arribas L, Vilajosana E, et al. The Multidisciplinary Team (MDT) Approach and Quality of Care. Front Oncol. 2020 Mar;10:85. https://doi.org/10.3389/fonc.2020.00085

3. Simon L, Tobey M, Wilson M. Feasibility of integrating a dental hygienist into an inpatient medical team for patients with diabetes mellitus. J Public Health Dent. 2019 Sep;79(3):188-92. https://doi.org/10.1111/iphd.12320

4. Gibney JM, Wright FA, D'Souza M, Naganathan V. Improving the oral health of older people in hospital. Australas J Ageing. 2019 Mar;38(1):33-8. https://doi.org/10.1111/ajag.12588

5. Kvalheim SF, Strand GV, Husebø BS, Marthinussen MC. End-of-life palliative oral care in Norwegian health institutions. An exploratory study. Gerodontology. 2016 Dec;33(4):522-9. https://doi.org/10.1111/ger.12198

6. Kaneoka A, Pisegna JM, Miloro KV, Lo M, Saito H, Riquelme LF, et al. Prevention of Healthcare-Associated Pneumonia with Oral Care in Individuals Without Mechanical Ventilation: A Systematic Review and Meta-Analysis of Randomized Controlled Trials. Infect Control Hosp Epidemiol. 2015 Aug;36(8):899-906. https://doi.org/10.1017/ice.2015.77

7. Epstein JB, Barasch A. Oral and dental health in head and neck cancer patients. Cancer Treat Res. 2018;174:43-57. https://doi.org/10.1007/978-3-319-65421-8_4

8. Mercadante S, Aielli F, Adile C, Ferrera P, Valle A, Fusco F, et al. Prevalence of oral mucositis, dry mouth, and dysphagia in advanced cancer patients. Support Care Cancer. 2015 Nov;23(11):3249-55. https://doi.org/10.1007/s00520-015-2720-y

9. Qutob AF, Allen G, Gue S, Revesz T, Logan RM, Keefe D. Implementation of a hospital oral care protocol and recording of oral mucositis in children receiving cancer treatment : a retrospective and a prospective study. Support Care Cancer. 2013 Apr;21(4):1113-20. https://doi.org/10.1007/s00520-012-1633-2

10. Gorges J, Wehler B, Krüger M, Singer S. [Oral health-related quality of life in cancer patients]. Laryngorhinootologie. 2018 May;97(5):327-33. Germany. https://doi.org/10.1055/a-0573-9741

11. Villa A, Akintoye SO. Dental management of patients who have undergone oral cancer therapy. Dent Clin North Am. 2018 Jan;62(1):131-42. ttps://doi.org/https://doi.org/10.1016/j.cden.2017.08.010

12. Zecha JA, Raber-Durlacher JE, Laheij AM, Westermann AM, Epstein JB, de Lange J, et al. The impact of the oral cavity in febrile neutropenia and infectious complications in patients treated with myelosuppressive chemotherapy. Support Care Cancer. 2019 Oct;27(10):3667-79. https://doi.org/10.1007/s00520-019-04925-8

13. Amaral CO, Belon LM, Silva EA, Amaral Filho MSP Straioto FG. The importance of hospital dentistry: oral health status in hospitalized patients. Rev Gaucha Odontol. 2018;66(1):35-41. https://doi.org/10.1590/1981-863720180001000053410

14. Alfonsín AE, Bordoni N, Salgado P, Squassi AF. Dynamics of the medical-dental relationship in a University Hospital in Buenos Aires, Argentina. Acta Odontol Latinoam. 2019 Aug;32(2):57-64.

15. Siegel RL, Miller KD, Jemal A. Cancer statistics, 2019. CA Cancer J Clin. 2019 Jan;69(1):7-34. https://doi.org/10.3322/caac.21551

16. Kattner P, Strobel H, Khoshnevis N, Grunert M, Bartholomae S, Pruss M, et al. Compare and contrast: pediatric cancer versus adult malignancies. Cancer Metastasis Rev. 2019 Dec;38(4):673-82. https://doi.org/10.1007/s10555-019-09836-y

17. Curra M, Soares Junior LA, Martins MD, Santos PS. Chemotherapy protocols and incidence of oral mucositis. An integrative review. Einstein (Sao Paulo). 2018;16(1):eRW4007. https://doi.org/10.1590/s1679-45082018rw4007

18. Nemes J, Jenei A, Marton I. Oral mucositis as the most common complication of childhood cancer therapy: review of the literature. Orv Hetil. 2018;159(13):495-502.https://doi.org/10.1556/650.2018.31011

19. Naidu MUR, Ramana GV, Rani PU, Mohan IK, Suman A, Roy P. Chemotherapy-induced and/or radiation therapy-induced oral mucositis: complicating the treatment of cancer. Neoplasia. 2004 Se'p;6(5):423-31. https://doi.org/10.1593/neo.04169

20. Basile D, Di Nardo P, Corvaja C, Garattini SK, Pelizzari G, Lisanti C, et al. Mucosal injury during anti-cancer treatment: from pathobiology to bedside. Cancers (Basel). 2019 Jun;11(6):857. https://doi.org/10.3390/cancers11060857

21. Gabriel DA, Shea T, Olajida O, Serody JS, Comeau T. The effect of oral mucositis on morbidity and mortality in bone marrow transplant. Semin Oncol. 2003 Dec;30(6 Suppl 18):76-83. https://doi.org/10.1053/i.seminoncol.2003.11.040

22. Bezinelli LM, Eduardo FP, Lopes RMG, Biazevic MG, Eduardo CP, Correa L, et al. Cost-effectiveness of the introduction of specialized oral care with laser therapy in hematopoietic stem cell transplantation. Hematol Oncol. 2014 Mar;32(1):31-9. https://doi.org/10.1002/hon.2050

23. Ranna V, Cheng KK, Castillo DA, Porcello L, Vaddi A, Lalla RV, et al. Development of the MASCC/ISOO clinical practice guidelines for mucositis: an overview of the methods. Support Care Cancer. 2019 Oct;27(10):3933-48. https://doi.org/10.1007/s00520-019-04891-1

24. Pandeshwar P, Roa MD, Das R, Shastry SP, Kaul R, Srinivasreddy MB. Photobiomodulation in oral medicine: a review. J Investig Clin Dent. 2016 May; $7(2): 114-26$. https://doi.org/10.1111/jicd.12148

25. Paglioni MP, Alves CG, Fontes EK, Lopes MA, Ribeiro AC, Brandão TB, et al. Is photobiomodulation therapy effective in reducing pain caused by toxicities related to head and neck cancer treatment? A systematic review. Support Care Cancer. 2019 Nov;27(11):4043-54 https://doi.org/10.1007/s00520-019-04939-2

26. Legouté F, Bensadoun RJ, Seegers V, Pointreau Y, Caron D, Lang P, et al. Low-level laser therapy in treatment of chemoradiotherapy-induced mucositis in head and neck cancer: results of a randomised, triple blind, multicentre phase III trial. Radiat Oncol. 2019 May;14(1):83. https://doi.org/10.1186/s13014-019-1292-2 
27. Zadik Y, Arany PR, Fregnani ER, Bossi P, Antunes HS, Bensadoun RJ, et al. Systematic review of photobiomodulation for the management of oral mucositis in cancer patients and clinical practice guidelines [Internet]. Support Care Cancer. 2019 Oct;27(10):3969-83. https://doi.org/10.1007/s00520-019-04890-2

28. Oliveira MC, Lebre Martins BN, Santos-Silva AR, Rivera C, Vargas PA, Lopes MA, et al. Dental treatment needs in hospitalized cancer patients: a retrospective cohort study. Support Care Cancer. 2020 Jul;28(7):3451-7. https://doi.org/10.1007/s00520-019-05202-4

29. Ní Chróinín D, Montalto A, Jahromi S, Ingham N, Beveridge A, Foltyn P. Oral health status is associated with common medical comorbidities in older hospital inpatients. J Am Geriatr Soc. 2016 Aug;64(8):1696-700. https://doi.org/10.1111/igs.14247

30. Kumar A, Rai A. Oral health status, health behaviour and treatment needs of patients undergoing cardiovascular surgery. Rev Bras Cir Cardiovasc. 2018 Mar-Apr;33(2):151-4. https://doi.org/10.21470/1678-9741-2017-0137

31. Bertaud-Gounot V, Kovess-Masfety V, Perrus C, Trohel G, Richard F. Oral health status and treatment needs among psychiatric inpatients in Rennes, France: a cross-sectional study [Internet]. BMC Psychiatry. 2013 Sep;13(1):227. https://doi.org/10.1186/1471-244X-13-227

32. Carrilho Neto A, Ramos SP, Sant'ana AC, Passanezi E. Oral health status among hospitalized patients. Int J Dent Hyg. 2011 Feb;9(1):21-9. https://doi.org/10.1111/j.1601-5037.2009.00423.x

33. Scully C, Miller CS, Urizar JMA, Alajbeg I, Almeida OP, Bagan JV, et al. Oral medicine (stomatology) across the globe: birth, growth, and future. Oral Surg Oral Med Oral Pathol Oral Radiol. 2016 Feb;121(2):149-157.e5. https://doi.org/10.1016/1.0000.2015.10.009

34. Almazrooa SA, Binmadi NO. The knowledge and attitude of physicians' toward the oral medicine specialty. J Oral Maxillofac Surg Med Pathol. 2021 Jan;33(1):214-20. https://doi.org/10.1016/i.ajoms.2020.07.014 